\title{
International Journal \\ of \\ English Studies
}

\section{Use of Language Learning Strategies by Spanish Adults for Business English}

\author{
JEFFREY WALLACE JUDGE* \\ Walden University
}

Received: 21 February 2011 / Accepted: 13 June 2011

\begin{abstract}
The aim of this phenomenological study was to explore the language learning strategies (LLSs) of Spanish adults in a business context. The research questions examined the specific LLSs used by Spanish adults in business communication tasks. In addition, this study addressed the cultural influences on LLSs from the Spanish educational system along with the influence from current and historical events in Spain. The conceptual framework was the Oxford LLS model. These qualitative data were collected through 11 semistructured, indepth interviews with Spanish business people who use English in their work and who studied English in Spanish secondary school. The data were analyzed following a typological analysis. The results show a strong tendency towards cognitive, metacognitive, and social strategies in business tasks. Cultural influences include the media, past political situation in Spain, and general issues in the English class in Spanish secondary schools.
\end{abstract}

KEYWORDS: Language learning strategies, business tasks, cultural influences, phenomenological research

\section{RESUMEN}

El objetivo de este estudio fenomenológico era el de explorar las estrategias de aprendizaje de un idioma (LLS) de adultos españoles dentro del contexto de la empresa. Las preguntas examinaban las LLS específicas utilizadas por los adultos españoles en tareas de comunicación comercia. Además, el estudio abordaba las influencias culturales del sistema educativo español sobre los LLS y las influencias de los eventos actuales e históricos de España. El marco conceptual era el de las LLS del modelo Oxford. Estos datos cualitativos se recogieron a través de 11 entrevistas semiestructuradas exhaustivas de empresarios españoles. Los datos se analizaron usando el análisis tipológico. Los resultados muestran una fuerte tendencia hacia estrategias cognitivas, metacognitivas y sociales en tareas laborales. Las influencias culturales abarcan los medios de comunicación, el pasado político español y temas generales de las clases de inglés de los centros de estudios secundarios españoles.

PALABRAS CLAVE: Estrategias de aprendizaje de un idioma, Tareas comerciales, Influencias culturales, Investigación fenomenológica

*Address for correspondence: Dr. Jeffrey Wallace Judge. Walden University alumnus; Camino de Francia 5; 08410 Vilanova del Vallès; Barcelona, Spain. Tel.: +34 605359 895. E-mail: jeff@jeffjudge.eu 


\section{INTRODUCTION}

Language learning strategy (LLS) research began in the 1970s with two studies by Rubin (1975) and by Stern (1975). Both authors studied similar questions: Rubin asked how successful language learners achieve success, and Stern asked what successful language learners do that the poor language learners do not do. More recently, Oxford (1990) wrote a foundational book on LLSs that is still used today as a reference point in the field due to its extensive taxonomy and its data collection tool. Oxford created six subcategories of LLSs: memory strategies, compensation strategies, cognitive strategies, metacognitive strategies, affective strategies, and social strategies. The other main contribution of Oxford's work was the development of the strategy inventory for language learning (SILL) for data collection in LLS research. The SILL is a quantitative questionnaire used to measure the frequency of strategy use in language learners.

In the recent literature on LLSs, studies have been conducted on numerous populations. In the Far East, researchers conducted studies on China (Bin, 2008; Gao, 2006; Jiang \& Smith, 2009; Jie \& Xiaoquing, 2006; Manfred, 2007; Nisbet et al., 2005; Parks \& Raymond, 2004; Quingquan et al., 2008; Rao, 2005; Rao, 2006; Yang, 2007), Japan (Cross, 2009; Grainger, 2005; Ikeda \& Takeuchi, 2006; Mizumoto \& Takeuchi, 2009; Nakatani, 2005; Nakatani, 2006; Yabukoshi \& Takeuchi, 2009), Korea (Hong-Nam \& Leavell, 2007 \& Lee \& Oxford, 2008), Taiwan (Chen, 2009; Hsiao, 2004; Ju, 2009; Lai, 2009; Wu, 2008; Yang, 2007), Thailand (Baker \& Boonkit, 2004), Indonesia (Lamb, 2004), Malaysia (Wong, 2005), Singapore (Zhang, Gu, \& Hu, 2008), and a combination of Confucian heritage cultures (Woodrow, 2005 \& Woodrow, 2006). In the Middle East, studies were conducted in Iran (Akbari \& Hosseini, 2008; Akbari \& Tahririan, 2009; Noormohamadi, 2009; Rahimi et al., 2008), Kuwait (Abou Baker El-Dib, 2004), Palestine (Khalil, 2005), Saudi Arabia (McMullen, 2009), Turkey (Saricoban \& Saricaoglu, 2008 \& Tercanlioglu, 2004), and Qatar (Riazi, 2007). In Africa, one researcher studied a population in Botswana (Mokuedi Magogwe \& Oliver, 2007). In North America, Brown (2006) conducted a LLS study on university students from the United States. In Western Europe Gallagher-Brett (2007) conducted a study on German language students in England. Only one study conducted research on a population in Western Europe (Gallagher-Brett, 2007) while no LLS research was conducted on Spaniards. Therefore, the absence of studies in this particular population revealed a gap in the literature.

In the reviewed literature, the LLS studies collected and analyzed data on numerous variables. The most common variable found in LLS research was proficiency level (Abou Baker El-Dib, 2004; Bin, 2008; Ikeda \& Takeuchi, 2006; Jie \& Xiaoquing, 2006; Ju, 2009; Khalil, 2005; Mokuedi Magogwe \& Oliver, 2007; Nisbet et al., 2005; Oxford et al., 2004; Quingquan et al., 2008; Rahimi et al., 2008; Saricoban \& Saricaoglu, 2008; Wu, 2008; Yabukoshi \& Takeuchi, 2009; Yang, 2007; Zhang et al., 2008). The next most researched 
variable was LLSs, that is, indentifying the LLSs of the population investigated (Akbari \& Tahririan, 2009; Alptekin, 2007; Bin, 2008; Brown, 2006; Jiang \& Smith, 2009; Lai, 2009; Manfred, 2007; Mokuedi Magogwe \& Oliver; Riazi, 2007; Saricoban \& Saricaoglu; Wong, 2005). The gender variable also appeared frequently in the literature in order to understand if men and women use LLSs differently (Abou Baker El-Dib, 2004; Graham, 2007; Lee \& Oxford, 2008; McMullen, 2009; Nisbet et al., 2005; Rahimi et al., 2008; Saricoban \& Saricaoglu, 2008; Tercanlioglu, 2004; Yabukoshi \& Takeuchi, 2009).

Numerous other variables appeared in the reviewed literature but with less frequency and repetition as in the case of the proficiency and gender variable. Such variables included multiple intelligence (Akbari \& Hosseini, 2008), skill based LLSs in vocabulary (Akbari \& Tahririan, 2009), reading (Ikeda \& Takeuchi, 2006 \& Zhang et al., 2008), and writing (Hung, 2009). Other variables included learning style (Chen, 2009; Jie \& Xiaoquing, 2006; \& Rahimi et al., 2008), grade level (Chen, 2009), age (Mokuedi Magogwe \& Oliver, 2007; Saricoban \& Saricaoglu, 2008; Zhang et al., 2008), student versus teacher perceptions of LLSs (Griffiths, 2007), monolingual versus bilingual students (Hong-Nam \& Leavell, 2007), major of study (Lee \& Oxford, 2008; McMullen, 2009), English learning self-image (Lee \& Oxford, 2008), self-efficacy beliefs (Mokuedi Magogwe \& Oliver, 2007; Wong, 2005), motivation (Manfred, 2007; Rahimi et al., 2008), student anxiety level (Noormohamadi, 2009), and years studying English (Rahimi et al., 2008).

In the area of culture, Riazi (2007) acknowledged the need to study various cultural backgrounds in LLS research, but very few articles actually collected data on culture. Four studies investigated the appropriateness of the SILL with their specific research population (Grainger, 2005; Lee \& Oxford, 2008; Rao, 2005; Rao, 2006). Grainger (2005) wanted to test the appropriateness of the SILL with Japanese students due to their orthographic writing system. Lee and Oxford (2008) inquired about the appropriateness of the SILL with Korean students while Rao (2005) and Rao (2006) wanted to test the SILL with Chinese students due to the susceptible Western bias of the SILL.

Only two articles in the literature review collected data on the influence of culture on LLSs (Lee \& Oxford, 2008; Rao, 2005). These articles sought to confirm the appropriateness of the SILL for their research population. Rao (2005) had specific research questions that inquired about the link between Chinese students LLSs and their cultural and educational background. In order to inquire about the cultural appropriateness of the SILL Rao (2005) used diaries and interviews. In the diaries, the research participants wrote their LLSs inside and outside the classroom for a one week period. Therefore, the diaries only identified LLS choice, but not cultural influences. In addition, Rao (2005) conducted interviews with the participants inquiring about their English learning experience. These interviews and the author's 10 years of EFL teaching in China helped Rao (2005) to understand the cultural influences on the Chinese student's LLSs. 
Lee and Oxford (2008) also collected data on the cultural factor. These researchers added two qualitative questions on the SILL in order to inquire about the cultural appropriateness of the SILL with Koreans. One of the qualitative questions asked the SILL participants to list any strategies that they employed and were not mentioned in the SILL. In the second qualitative question, the researchers asked the participants to list any strategy in the SILL that was particularly difficult to use in the Korean EFL context. Lee and Oxford (2008) added these two qualitative questions to the SILL for a twofold purpose. First, they wanted to encounter any relationship between LLS use and culture. Second, they wanted to check the validity of the SILL in an EFL environment where EFL students have limited opportunities to speak with native English speakers.

Some of the researchers in the reviewed literature indicated a need for more qualitative research methods in LLSs (Abou Baker El-Dib, 2004; Lai, 2009; Quingquan et al., 2008; Tseng et al., 2006; Wong, 2005; Woodrow, 2005). Abou Baker El-Dib (2004) explained that interviews may be the best way to measure the LLSs of students. Akbari and Tahririan (2009) mentioned that interviews could obtain information that other methods could not reveal. Interviews are useful to probe students for more detail (Gallagher-Brett, 2007), to confirm their understanding of a quantitative questionnaire (Baker \& Boonkit, 2004), to gain deeper insight into LLSs (Quingquan et al., 2008 \& Wong, 2005), and to provide clarification (Grainger, 2005). Therefore, it appears that many researchers agree with the need for qualitative research in the field of LLSs along with the effectiveness of interviews as a data collection tool.

Cohen and Macaro (2007) edited a book that reviewed the research and practice of LLS over the last 30 years. The book provides a comprehensive dialogue of LLS since inception in the 1970s. The book employed a systemic review process to ensure the inclusion of all relevant LLS research, including the following areas: listening, reading, speaking, writing, and vocabulary.

The present study was pursued for two reasons: (a) the lack of knowledge in business English LLSs of Spanish adults, and (b) the importance of English in Europe. In reference to the first reason, none of the studies in the background literature focused on the specific culture of Spanish adults or in the area of business English tasks. Therefore, this study contributed to the LLS knowledge base by exploring LLSs in the business tasks of Spanish adults.

The second reason to pursue this study was due to the importance of English in Europe. The use of English in Europe affects not only business but also education, research, and international relations. English has become Europe's lingua franca (Hofstede, 2001), the most commonly used language when Europeans of distinct first languages communicate (Breiteneder, 2008). Due to this high importance of English in Europe, many business tasks such as meetings, presentations, phone calls, and e-mails are conducted in English throughout Europe. Furthermore, the ability to communicate in English can influence an employee's advancement opportunities in a company (Desai, 2008). 


\section{METHOD}

The purpose of this phenomenological study was to explore the common and shared experiences of Spanish adults in using LLSs while engaged in business communication tasks. The conceptual framework in this study was Oxford's (1990) LLS model. Oxford's model was chosen due to its thorough categorization of LLSs and for its frequent mention and use in the literature. Oxford divided LLSs into six groups: memory, cognitive, compensation, metacognitive, social, and affective strategies.

\subsection{Research questions}

The following research questions guided this study:

1. What is the shared experience among Spanish adults who use English for business purposes in preparing for business tasks conducted in English?

2. What language learning strategies do Spanish adults use in the following business tasks in English: delivering presentations, writing e-mails, participating in conference calls, attending meetings, and conducting one-to-one telephone calls?

3. What language learning strategies do Spanish adults use outside the work environment?

4. What influences does the Spanish culture have on Spanish adults who are learning English as a second language?

The specific areas of culture explored were English teaching within the Spanish educational system, historical events in Spain, and general cultural influences as understood by the participants.

\subsection{Participants}

Purposeful sampling was employed to ensure that participants met certain criteria. All participants were Spanish, non-native English speakers who used English in their work for business communication purposes such as delivering presentations, writing e-mails, attending meetings, and using the telephone in English. In addition, they studied English during their Spanish secondary school education. I used pseudonyms in the study write up to ensure confidentiality.

I interviewed 11 participants following Creswell's (2007) suggestion of using 10 participants in a phenomenological study. This number of participants was enough to provide a saturation of the data as I discovered in previously conducted pilot studies on the same topic. 


\subsection{Data collection and recording tools}

The data collection tool used in this present study was interviews. Qualitative interviews are characterized by an informal, comfortable, and interactive style with open-ended questions following an interview guide (Moustakas, 1994). I chose interviews as a data collection tool due to their ability to reveal information that other data collection tools are incapable of revealing. In addition, interviews can help understand the phenomenon from the interviewee's perspective (Hatch, 2002).

\subsubsection{Data Collection Steps}

Creswell (2007) detailed the steps to interviewing that I followed in this present study. First, I identified potential interviewees by employing purposeful sampling. Next, I decided to conduct on-site one-to-one interviews but offered to conduct phone interviews as well. All the participants preferred on-site interviews. I used a digital recording device to record the interviews, which I had tested and found effective in previously conducted pilot interviews. I followed an interview guide in order to cover the issues in the research questions.

I established the first contact with potential participants with an invitation to participate e-mail. This e-mail explained the purpose of the study along with the participant criteria. The e-mail also mentioned the location of the interview, which Creswell (2007) emphasized as being an important step in the data collection process. I initially contacted 18 potential participants to account for possible no responses or potential participants who were not available for the interviews. I was going to interview the first 10 potential participants that confirmed participation. In the end, I interviewed 11 participants due to an unexpected positive response from 11 of the 18 participants.

The interviews were conducted in the offices of the interviewees or in a meeting room in the interviewee's company. I sent each interviewee a consent form by e-mail before the interview. After the interviews, I transcribed the interviews as soon as possible, as suggested by Hatch (2002). I gave each interviewee a pseudonym (Rubin \& Rubin, 2005) in order to protect the confidentiality of the interviewees.

\subsubsection{Data analysis and interpretation plan}

The data analysis and interpretation plan in this study followed Hatch's (2002) description of a typological analysis due to the predetermined categories already established in this study. The categories that $\mathrm{I}$ used in the initial data analysis were the following business communication tasks: presentations, e-mails, meetings, conference calls, and one-to-one telephone calls. In addition, further categories included the following: additional English language development activities conducted outside work, motivation factors to continue learning English, and cultural influences on the language learning process. In the category of 
cultural influences, I subdivided this area into further categorizations including: the English language learning context in Spanish secondary school, historical issues, and current events.

Language learning strategies (Oxford, 1990) are generally defined as techniques implemented by learners to increase their knowledge, understanding, and use of a second or foreign language. The use of LLSs by learners increases their independence in the learning process.

In the first step of the data analysis, I read all 11 transcripts and identified each participant's LLSs used in business communication tasks along with describing the other previously mentioned typologies. All of the typologies were written in a data analysis matrix so that each participant's answers could be compared to the rest of the participants in order to examine the shared experiences of the participants. Next, I read the typologies of each participant individually and then provided a summary of each typology per participant, along with coding the LLSs of each participant per typology. Then I searched for LLS patterns by reading each typology across the 11 participants.

In the following step, I coded the identified hypothetical patterns by rereading each typology. In order to ensure the quality of the coding and the patterns, I returned to the data in order to confirm or disconfirm these findings. Following this step, I wrote generalizations for each pattern that included examples from the raw data. I conducted follow up with participants when needed for clarification purposes. In the following write up, I used the exact words of the participants despite some awkward phrasing in order to allow the voice of the participants to be heard. Therefore, I adhered to the raw data gained from the interview process in order to ensure the quality of this data collection tool.

Qualitative inquiry focuses on establishing the trustworthiness of the study to ensure against the threats to validity (Creswell, 2007). Lincoln (1995) mentioned several criteria for improving the quality of qualitative research, which I implemented in the research process. Lincoln acknowledged the relational aspect between the researcher and the research participants. One specific criterion she mentioned was that of voice. A quality standard in qualitative enquiry provides a voice for populations that are generally absent. As explained earlier, the Spanish population did not appear in any studies in the literature review on LLSs. Therefore, this study provided a voice for this under-researched population.

\section{RESULTS}

\subsection{Question 1}

What is the shared experience among Spanish adults who use English for business purposes in preparing for business tasks conducted in English?

This question was asked to explore the common LLSs that all the participants employed while preparing for business tasks in English. The participants in this study shared common patterns of LLS use in the business English communication tasks. The three main 
LLSs that were shared across the participants were social, cognitive, and metacognitive strategies. I discovered patterns that indicated the absence of use of memory, affective, and compensation strategies. Social strategies emphasize interaction with others in the language learning process. Cognitive strategies refer to the mental processing while sending and receiving messages in a foreign language. Metacognitive strategies indicate an emphasis on planning, preparing, and structuring the learning process (Oxford, 1990).

In the interviews, the evidence of these three strategies appeared in all of the business communicates categories. For example, for social strategies when referring to emails Montse said, "I show to some colleague that had a better level than mine". To prepare for presentations, Ariadna said, "usually if it's a presentation for the affiliates as they come here for two days I usually prefer to do it (the presentation) the second day because first I can go and have lunch with them and for me it's easier when I know the people". Referring to conference calls, Tomás said, "when I have conference calls, fortunately I'm not alone. I'm with other mates from my work".

Cognitive strategies also appeared across all business communication categories. For example, Albert takes notes before a conference call by writing down "how to introduce myself or how I close the conference or how I can ask them some things". For presentations María said, "I would try to summarize the main topics. I would try to do some structure in a brief summary", which corresponds to Oxford's (1990) cognitive strategy of creating structure by summarizing. Tomás uses resources for sending emails. He said, "I can use dictionaries, on my laptop I can use Google translator or word reference and other ones". Using resources for receiving and sending messages corresponds to cognitive strategies according to Oxford (1990).

Metacognitive strategies also appeared across all the business communication categories. One metacognitive strategy according to Oxford (1990) is self evaluating. Tomás demonstrated this strategy with emails when he said, "when I have to write, I try to write simple. I read what I write and then I correct my mistakes". Ismael concurred by saying, "I reread what I have written there in terms of if there is any mistake".

The shared experience among Spanish adults also indicates a lack of preference for memory, affective, and compensation strategies. Memory strategies assist students with remembering language for long-term memory. Affective strategies deal with becoming aware of feelings and attitudes in the language learning process. Compensation strategies allow learners to counterbalance gaps in their language knowledge.

\subsection{Question 2}

What language learning strategies do Spanish adults use in the following business tasks in English: delivering presentations, writing e-mails, participating in conference calls, attending meetings, and conducting one-to-one telephone calls? 
I referred to the data analysis matrix and summary chart in each task in order to examine the patterns and provide examples of the patterns from the interviews. Several themes emerged in each business English task. Four main themes emerged across the responses about preparing for and delivering presentations. The four themes for presentations were the following: the importance of preparing a structure for the presentation, the importance of practicing the presentation, the importance of simplifying the presentation as much as possible, and the importance of assessing the audience, specifically the cultural background of the audience.

Several themes appeared in the area of writing e-mails. The themes for writing emails were the following: the importance of using tools, the importance of using expressions from the e-mails of native speakers and colleagues, the importance of simplifying their e-mails, and the importance of providing clear structure.

In order to prepare for conference calls, the research participants explained specific techniques that they apply before, during, and after the conference call. Before the conference call, participants conducted a general review of all important documents pertaining to the call and practiced key phrases and expressions for the conference call. During the conference call, participants would clarify to ensure their understanding of the speaker when they had a difficult time following a speaker's accent. In addition, some of the research participants employed other strategies to follow the conversation such as creating a guide to follow. One participant recorded each conference call in order to consult the recording for clarifying purposes.

In the business communication task of meetings, the participants offered different strategies and techniques that they employ before and during a meeting. Before the meeting, the participants prepare in various ways. The participants emphasized the importance of preparing paperwork before the meeting and convening with their own team before the actual meeting. Some participants explained the importance of preparing opening expressions such as greetings and personal introductions. Another area of preparation for meetings included listening and speaking practice. Some participants increased the amount of English listening input several days before an important meeting by listening to web podcasts.

During a meeting, the participants employed several strategies. To follow the meeting, participants clarified frequently to ensure understanding. In addition, participants paid special attention to speakers with difficult accents. Other participants explained the importance of mentally formulating and clarifying what one wants to say before speaking, which avoids improvisation.

In the final business communication task, one-to-one telephone calls, the participants offered different strategies. Several of the participants prepared before the call by writing notes, writing possible responses to situations or writing what an ideal phone call would entail. Another technique included having all relevant documents handy before making the call. During the call, several of the participants employed specific strategies such as speaking 
slowly and simplifying sentence structures. In addition, some participants mentioned the importance of having a strong and clear voice tone in order to transmit a good, competent image.

\subsection{Question 3}

What language learning strategies do Spanish adults use outside the work environment?

During the interviews, I specifically asked all the participants how they developed and improved their English outside the work environment. I asked this question to discover the best practices outside the work environment of the research participants. Understanding these best practices could help current EFL students in their own self-directed learning tasks. One of the most common themes among all the participants was reading in English. The participants read books, magazines, and the internet frequently in English. Another way was by watching television and films in English. The participants made an intentional effort to watch movies and TV in English, never missing an opportunity to listen to the original version. Third, some of the participants practiced their English by speaking with native English speaking friends. Therefore, the participants sought out practice opportunities outside the work environment.

\subsection{Question 4}

What influences does the Spanish culture have on Spanish adults who are learning English as a second language?

This question was asked to explore the possible cultural influences on LLS use in Spain. In the interviews, the themes that appeared in the data for the research question about culture were the media, the past dictatorship, and the educational system. Six of the participants explained that the lack of original version television and films negatively influenced the improvement of English in Spain. Five of the participants admitted that the past dictatorship in Spain created a barrier for the development of English, affecting the current state of English in Spain. In addition, five of the participants also mentioned that the Spanish educational system does not provide adequate and quality teaching.

Referring to television and movies, the participants acknowledged the difficulty in Spain to find TV and films in original version compared to other European Union (EU) countries. In regards to the past Spanish dictatorship, some of the participants explained how Spain was separated from the rest of Europe during that time, therefore placing Spain behind other EU countries in terms of exposure to English. The participants indicated several problems with the Spanish educational system, slowing the progress of English in Spain. Traditionally, problems included a lack of English speaking opportunities in the English classroom, the large size of the English classroom, the lack of interactive teaching methodology conducted in the class, and the absence of LLSs taught in the classroom. In 
addition, most of the participants explained that the main language spoken by teachers and students in the English classroom was not English, but rather Spanish.

\section{DISCUSSION}

In the first research question about the shared experience among Spanish adults who use English for business purposes in preparing for business tasks conducted in English, the findings revealed an emphasis on social, cognitive, and metacognitive strategies among the participants with an absence of memory, affective, and compensation strategies. The results of this study reflect similar results from some studies in the reviewed literature (Lai, 2009; Mokuedi Magogwe and Oliver, 2007; Riazi, 2007; Wong, 2005).

On the other hand, some studies in the reviewed literature produced differing results (Alptekin, 2007; Brown, 2006; Jiang and Smith, 2009; Saricoban and Saricaoglu, 2008). Alptekin (2007) conducted a quantitative study on Turkish students and found that compensation strategies were most frequently used. Brown (2006) conducted a qualitative study and discovered that participants most frequently chose affective strategies. Jiang and Smith (2009) conducted a qualitative study and discovered that participants most frequently employed memorization strategies. Saricoban and Saricaoglu (2008) conducted a quantitative study on Turkish students and teachers and concluded that their participants most frequently employed metacognitive and compensation strategies. The use of metacognitive strategies coincides with the results of this current study while the use of compensation strategies does not coincide with this current study.

In relation to Oxford's (1990) LLS theory, the findings agree with some of the concepts expressed by Oxford. Oxford expressed that cognitive strategies have the tendency of being frequently employed by language learners, thus agreeing with the results of this current study. Oxford explained that memory and affective strategies have been reported to be less frequently employed strategies by language learners, again agreeing with the results of this study. Oxford indicated that memory strategies may not be frequently employed beyond an elementary foreign language level. Referring to compensation strategies, Oxford explained that lower level students would employ compensation strategies more frequently due to their greater lack of knowledge. The results of this current study concur as the participants did not employ compensation strategies frequently. The participants had a high level of English language competence and therefore did not need to rely on compensation strategies due to the limited gaps in their language knowledge.

Oxford (1990), referring to metacognitive strategies, noted, "learners use these strategies sporadically" (p. 138). The findings of this current study indicate that the Spanish adults used metacognitive strategies consistently among all business communication tasks, thus disagreeing with Oxford's comments about metacognitive strategy use. Regarding social 
strategies, Oxford explained that the school system may discourage social strategies such as cooperating with others due to competitive activities that encourage individual performance and recognition. The participant interviews from this current study did not indicate the use of competitive activities in the English language classroom in Spain. On the contrary, some of the participants indicated a lack of interactive activities.

Contrary to Oxford's (1990) comment about the school discouraging social strategies, the participants frequently employed social strategies such as cooperating with peers and proficient language users during business communication tasks. Cultural factors, such as a tendency towards collectivism in Spain (Hofstede, 2001) may actually encourage these social strategies in collectivist cultures.

In summary, the participants of this present study frequently employed social, cognitive, and metacognitive strategies, concurring with some of the studies in the LLS literature (Lai, 2009; Mokuedi Magogwe \& Oliver, 2007; Riazi, 2007; Wong, 2005). In addition, the participants of this study demonstrated a lack of use of some strategies such as memory, compensation, and affective strategies, differing from the results of studies conducted in Turkey (Alptekin, 2007; Saricoban \& Saricaoglu, 2008), China (Jiang \& Smith, 2009), and the United States (Brown, 2006).

The second research question was: What language learning strategies do Spanish adults use in the following business tasks in English: delivering presentations, writing e-mails, participating in conference calls, attending meetings, and conducting one-to-one telephone calls? The third research question was: What language learning strategies do Spanish adults use outside the work environment? I will combine these two questions together in this discussion due to their similar task based approach to LLSs. In the reviewed literature, several studies also focused on specific language learning tasks of the participants. None of the tasks in the reviewed literature were business communication tasks but rather focused on vocabulary (Akbari \& Tahririan, 2009), reading (Ikeda \& Takeuchi, 2006 \& Zhang et al., 2008), and writing (Hung, 2009). These studies provided the closest point of reference in order to draw conclusions from the literature on research questions 2 and 3 in this current study. All of these task based studies employed a qualitative research design as in this current study.

Akbari and Tahririan (2009) conducted a qualitative study on Iranian students with the purpose of creating a vocabulary learning strategy taxonomy. These authors used an existing taxonomy that contained two main categories; comprehension and learning/acquisition strategies. The taxonomy subdivided these categories further into subcategories, similar to Oxford's (1990) LLS categorization. These authors explained which subcategories the students used, such as oral/written repetition. Two studies focused on reading tasks (Ikeda \& Takeuchi, 2006 \& Zhang et al., 2008). Ikeda and Takeuchi (2006) conducted a qualitative study on Japanese females while Zhang et al. (2008) conducted a study on Singaporean children. Hung (2009) conducted a qualitative case study on the writing learning strategies of 
two participants in Taiwan. Hung analyzed the data by coding three main typologies: learners' English learning background, learners' writing strategies, and learners' self-assessment practices. Hung explained the different categories of writing strategies used in the study and demonstrated examples from the data of how the participants employed these strategies.

In my study, I focused on how the research participants prepared for and engaged in their business communication activities in English. I followed Swan's (2008) approach to LLSs by presenting the LLSs of the participants in each business communication task in the form of "ways of" preparing for and delivering presentations, meetings, etc... As a brief summary, here I demonstrate some of the ways the participants prepare for and engage in these business communication tasks.

For presentations, María would prepare by "talking aloud to myself in an empty room and repeat the introduction, body and conclusions for myself". Montse practiced in a similar way when she said, "once I have the idea I try to practice alone and then afterwards I have my partner or a colleague or someone". For meetings, Ismael said, "what you do in a meeting is you try to speak when you are sure about what you are going to say". Albert prepares for conferences calls by writing down specific expressions "to introduce myself or how I close the conference or how I can ask them some things". Juan practices his English outside the work environment by reading "a lot in English. Whenever I can I watch movies in English and I also talk in English with English speaking friends".

The fourth research question was: What influences does the Spanish culture have on Spanish adults who are learning English as a second language? To address this question in the context of the reviewed literature, I referred to two articles that collected data on cultural influences and LLSs (Lee \& Oxford, 2008 \& Rao, 2005). These articles collected data on the influence of culture in relation to the appropriateness of the SILL with their research population. Therefore, these studies did not specifically explore the cultural influences on LLSs as in this current study but did provide insight into the cultural biases of the SILL.

Rao (2005) conducted a case study with 20 Chinese participants and collected data through participant diaries and interviews in an attempt to modify the SILL to be more culturally appropriate for Chinese EFL students. As a result of the study, Rao eliminated 17 of the original 80 SILL items since the 17 rejected items were considered "unpopular" (p. 53) among the participants. Rao replaced the 17 eliminated items with 17 new items proposed by the participants that did not appear in the original SILL. Lee and Oxford (2008) conducted a similar study with Korean students. They discovered that some of the social strategies were difficult for the participants to employ due to the lack of native speakers in their environment.

Jiang and Smith (2009) and Lai (2009) did not collect data on the cultural influences of LLSs but explained the various influences on a student's LLS choice that I discovered in this current study. Jiang and Smith (2009) noted that the teachers' methodology impacted a students' LLS use, along with language policy. Lai (2009) also mentioned the influence of the teachers' methodology along with the English language educational system. In this current 
study, within the influence of the Spanish culture on Spanish adults learning English, I explored the influence of the Spanish educational system. I discovered that the participants' choice of LLSs in business communications was not necessarily the LLSs taught or used in secondary school.

I discovered that most of the English teachers in Spanish secondary school did not teach specific LLSs in the English classroom. The teachers that taught LLSs used memorization strategies in the form of flashcards with vocabulary or grammar. Bea explained what her teacher did with memorization strategies. "We had to prepare these little cards with the 3 tenses of the verbs and we put them through a binder. We had a lot of these cards and there are all the verbs and they were in three different colors so we would have yellow cards for irregular groups and we would have white cards for the regular groups".

Surprisingly, the participants did not employ memory strategies frequently in their business communication tasks. Therefore, I would extend Jiang and Smith (2009) and Lai's (2009) comments on the influence of culture on LLS use by asking how culture influences these strategies. Perhaps the frequent use of some strategies in an educational system, like memory strategies in Spain, causes students to later reject these strategies in adulthood.

In addition, one of the patterns that I detected was the lack of speaking activities and interactive methodology in Spanish secondary school indicating a lack of employed social strategies. Jordi demonstrated this when he said, "when I was 17 and 18, they tried to do everything in English but the other years it was a Spanish speaking class with everything on paper". In the data analysis, I discovered that social strategies were frequently employed by the participants during business communication tasks. Therefore, it appears that the LLSs used in adulthood are not necessarily the LLSs used in secondary school.

On the other hand, from the data analysis I discovered that many of the classroom activities in Spanish secondary school focused on cognitive strategies such as translating and analyzing grammar. Albert demonstrated this grammar focus when he said that his English class was, "all grammar, all the time with grammar. It was typical in the 70s. The teacher started with the verb 'to be' on the blackboard in the first class". Therefore, cognitive strategies were frequently used in the English classroom in Spanish secondary school and employed by the participants during business communication tasks.

\section{CONCLUSION}

Spanish adults who use English for business communication tasks focus on social, cognitive, and metacognitive strategies. They employ a variety of actions in preparing for and conducting these tasks, such as cooperating with peers, using numerous resources, and organizing their tasks. They did not employ many affective, compensation, or memory strategies. The participants provided rich data into specific strategies they employ before and 
during their business communication tasks in English that can be used to help EFL teachers and students alike in Spain and similar countries.

The participants demonstrated a sense of purpose, structure, and organization in their business communication tasks. María demonstrates this point when she said, "if you want to learn you must be very pro-active". María worked on her presentations by "preparing always a structure, the introduction, the body". Bea demonstrated this sense of structure with her emails when she said, "I structure my e-mails". While referring to meetings Ariadna said, "first of all I think I would prepare an agenda to see which are the points that are going to be treated during the meeting".

The participants also demonstrated a cultural awareness beyond the Spanish borders as demonstrated by Juan, "I've traveled a lot so I know what Spain represents". Tomás expressed this importance of cultural awareness when he said, "we have to understand other people". He continued his thought by saying, "it's like I want to be a citizen of the world and that's why I think it's good to improve my English". In addition to cultural awareness, the participants recognized the importance of English as seen in Jordi's comment, "you are not a responsible person if you don't try to understand English". Ariadna said, "you need it (English) for everything today". The participants recognized the importance and use of English not only in the work environment, but in all aspects of their lives. In conclusion, Spanish adults engaged in business communication tasks in English employ a variety of LLSs, have cultural awareness, and an understanding of the importance of English to achieve competence in these tasks.

\section{REFERENCES}

Abou Baker El-Dib, M. (2004). Language learning strategies in Kuwait: Links to gender, language level, and culture in a hybrid context. Foreign Language Annals, 37(1), 85-95.

Akbari, R., \& Hosseini, K. (2008). Multiple intelligences and language learning strategies: Investigating possible relations. System, 36(2), 141-155.

Akbari, Z., \& Tahririan, M. N. (2009). Vocabulary learning strategies in an ESP context: The case of Para/medical English in Iran. Asian EFL Journal, 11(1), 39-61.

Alptekin, C. (2007). Foreign language learning strategy choice: Naturalistic versus instructed language acquisition. Journal of Theory and Practice in Education, 3(1), 4-11.

Baker, W., \& Boonkit, K. (2004). Learning strategies in reading and writing: EAP contexts. Regional Language Centre Journal RELC Journal, 35(3), 299-328.

Bin, X., (2008). Application of learning strategies and college English reading achievements. USChina Foreign Languages, 6(5), 39-45.

Breiteneder, A. (2008). English as a lingua franca in Europe: An empirical perspective. World Englishes, 28(2), 256-269.

Brown, J. (2006). Locus of learning and affective strategy use: Two factors affecting success in selfinstructed language learning. Foreign Language Annals, 39(4), 640-659.

Chamot, A. U., \& Kupper, L. (1989). Learning strategies in foreign language instruction. Foreign Language Annals, 22(1), 13-22. 
Chen, M. L. (2009). Influence of grade level on perceptual learning style preferences and language learning strategies of Taiwanese English as a foreign language learners. Learning and individual differences, 19, 304-308.

Cohen, A. \& Macaro, E. (Eds.) (2007). Language learner strategies: 30 years of research and practice. Oxford: Oxford University Press.

Creswell, J. W. (2007). Qualitative inquiry \& research design: Choosing among five approaches. $\left(2^{\text {nd }}\right.$ edition). Thousand Oaks, CA: Sage Publications.

Cross, J. (2009). Effects of listening strategy instruction on news videotext comprehension. Language Teaching Research, 13(2). 151-176.

Desai, D. (2008). Globalization and the English skills gap. Chief Learning Officer, 7(6), 62-63.

Gallagher-Brett, A. (2007). What do learners' beliefs about speaking reveal about their awareness of learning strategies? Language Learning Journal, 35(1), 37-49.

Gao, X. (2006). Understanding changes in Chinese students' uses of learning strategies in China and Britain: A socio-cultural re-interpretation. System, 34(1), 55-67.

Graham, S. (2007). Learner strategies and self-efficacy: making the connection. Language Learning Journal, 35(1), 81-93.

Grainger, P. (2005) Second language learning strategies and Japanese: Does orthography make a difference? System, 33(2), 327-339.

Griffiths, C. (2007). Language learning strategies: students' and teachers' perceptions. ELT Journal, 61(2), 91-99.

Hatch, J. A. (2002). Doing qualitative research in education settings. Albany, NY: State University of New York Press.

Hofstede, G. (2001). Culture's consequences: Comparing values, behaviors, institutions, and organizations across nations ( ${ }^{\text {nd }}$ ed.). Thousand Oaks, CA: Sage Publications Ltd.

Hong-Nam, K., \& Leavell, A. G. (2007). A comparative study of language learning strategy use in an EFL context: Monolingual Korean and bilingual Korean-Chinese university students. Asia Pacific Education Review, 8(1), 71-88.

Hsiao, T. Y. (2004). Testing a social psychological model of strategy use with students of English as a foreign language. Psychological Reports, 95, 1059-1071.

Hung, S. T. (2009). Promoting self-assessment strategies: an electronic portfolio approach. Asian EFL Journal, 11(2), 129-146.

Ikeda, M., \& Takeuchi, O. (2006). Clarifying the differences in learning EFL reading strategies: An analysis of portfolios. System, 34(3), 384-398.

Jiang, X., \& Smith, R. (2009). Chinese learners' strategy use in historical perspective: A crossgenerational interview-based study. System, 37(2), 286-299.

Jie, L., \& Xiaoquing, Q. (2006). Language learning styles and learning strategies of tertiary-level English learners in China. RELC Journal, 37(1), 67-90.

Ju, C. Y. (2009). In-service adult learners' English learning strategies in Taiwan. The International Journal of Learning, 16(19), 119-132.

Khalil, A. (2005). Assessment of language learning strategies used by Palestinian EFL learners. Foreign Language Annals, 38(1), 108-119.

Lai, Y. C. (2009). Language learning strategy use and English proficiency of university freshman in Taiwan. TESOL Quarterly, 43(2), 255-280.

Lamb, M. (2004). 'It depends on the students themselves': Independent language learning at an Indonesian state school. Language, Culture and Curriculum, 17(3), 229-245.

Lee, K. R., \& Oxford, R. (2008). Understanding EFL learners' strategy use and strategy awareness. Asian EFL Journal, 10(1), 7-32.

Lincoln, Y. S. (1995). Emerging criteria for quality in qualitative and interpretive research. Qualitative Inquiry, 1(3), 275-289.

Manfred, W.M.F. (2007). The relationships between the use of metacognitive language-learning strategies and language-learning motivation among Chinese-speaking ESL learners at a vocational education institute in Hong Kong. Asian EFL Journal, 9(3), 93-117.

Mizumoto, A., \& Takeuchi, O. (2009). Examining the effectiveness of explicit instruction of vocabulary learning strategies with Japanese EFL university students. Language Teaching Research, 13(4), 425-449. 
Mokuedi Magogwe, J., \& Oliver, R. (2007). The relationship between language learning strategies, proficiency, age and self-efficacy beliefs: A study of language learners in Botswana. System, $35(2), 338-352$.

Moustakas, C. (1994). Phenomenological research methods. Thousand Oaks, CA: Sage Publications, Inc.

Nakatani, Y. (2005). The effects of awareness-raising training on oral communication strategy use. Modern Language Journal, 89(i), 76-91.

Nakatani, Y. (2006). Developing an oral communication strategy inventory. Modern Language Journal, 90(ii), 151-169.

Nisbet, D. L., Tindall, E. R., \& Arroyo, A. A. (2005). Language learning strategies and English proficiency of Chinese university students. Foreign Language Annals, 38(1), 100-107.

Noormohamadi, R. (2009). On the relationship between language learning strategies and foreign language anxiety. Pan-Pacific Association of Applied Linguistics, 13(1), 39-52.

Oxford, R. (1990). The good language learner: What every teacher should know. New York: Newbury House Publishers.

Oxford, R. L. (1993). Research on second language learning strategies. Annual Review of Applied Linguistics, 13, 175-187.

Oxford, R. Cho, Y, Leung, S., \& Kim, H.J. (2004). Effect of the presence and difficulty of task on strategy use: an exploratory study. International Review of Applied Linguistics in Language Teaching, 42(1), 1-47.

Parks, S., \& Raymond P. M. (2004). Strategy use by nonnative English-speaking students in an MBA program: not business as usual. Modern Language Journal, 88(Iii), 374-389.

Rahimi, M., Riazi, A., \& Saif, S. (2008). An investigation into the factors affecting the use of language learning strategies by Persian EFL learners. Canadian Journal of Applied Linguistics, 11(2), $31-60$.

Rao, Z. (2005). Adapting the SILL (strategy inventory for language learning) to suit students in a Chinese context. Hong Kong Journal of Applied Linguistics, 10(2), 52-70.

Rao, Z. (2006). Understanding Chinese students' use of language learning strategies from cultural and educational perspectives. Journal of Multilingual \& Multicultural Development, 27(6), 491508.

Riazi, A. (2007). Language learning strategy use: Perceptions of female Arab English majors. Foreign Language Annals, 40(3), 433-440.

Rubin, J. (1975). What the 'good language learner' can teach us. TESOL Quarterly, 9(1), 41-51.

Rubin, H. J., \& Rubin, I. S. (2005). Qualitative interviewing: The art of hearing data ( $\left.2^{\text {nd }} \mathrm{ed}.\right)$. Thousand Oaks, CA: Sage Publications, Inc.

Saricoban, A., \& Saricaoglu, A. (2008). The effect of the relationship between learning and teaching strategies on academic achievement. Novitas-Royal, 2(2), 162-175.

Stern, H.H. (1975). What can we learn from the good language learner? Canadian Modern Language Review, 31(4), 304-318.

Swan, M. (2008). Talking sense about learning strategies. Regional Language Centre Journal RELC Journal, 39, 262-273.

Tercanlioglu, L. (2004). Exploring gender effect on adult foreign language learning strategies. Issues in Educational Research, 14(2), 181-193.

Tseng, W. T., Dörnyel, Z., \& Schmitt, N. (2006). A new approach to assessing strategic learning: The case of self-regulation in vocabulary acquisition. Applied Linguistics, 27(1), 78-102.

Wenden, A. L. (1986). What do second-language learners know about their language learning? A second look at retrospective accounts. Applied Linguistics, 7(2), 186-204.

Wong, M. S. L. (2005). Language learning strategies and language self-efficacy: Investigating the relationship in Malaysia. Regional Language Centre Journal: RELC, 36(3), 245-269.

Woodrow, L. (2005). The challenge of measuring language learning strategies. Foreign Language Annals, 38(1), 90-99.

Woodrow, L. J. (2006). A model of adaptive language learning. Modern Language Journal, 90(3), 297-319.

Wu, Y.L. (2008). Language learning strategies used by students at different proficiency levels. Asian EFL Journal, 10(4), 75-95. 
Yabukoshi, T., \& Takeuchi, O. (2009). Language learning strategies used by lower secondary school learners in a Japanese EFL context. International Journal of Applied Linguistics, 19(2), 136 172.

Yang, M. N. (2007). Language learning strategies for junior college students in Taiwan: Investigating ethnicity and proficiency. Asian EFL Journal, 9(2), 35-57.

Zhang, L. J., Gu, P. Y., Hu, G., (2008). A cognitive perspective on Singaporean primary school pupils' use of reading strategies in learning to read in English. British Journal of Educational Psychology, 78, 245-271. 